\title{
Microstructure, Texture Evolution and Mechanical Properties of VT3-1 Titanium Alloy Processed by Multi-Pass Drawing and Subsequent Isothermal Annealing
}

\author{
Xiaofei Lei ${ }^{1,2}$, Limin Dong ${ }^{1, *}$, Zhiqiang Zhang ${ }^{1}$, Yujing Liu ${ }^{3}$, Yulin Hao ${ }^{1}$, Rui Yang ${ }^{1}$ and \\ Lai-Chang Zhang ${ }^{3, *}$ \\ 1 Institute of Metal Research, Chinese Academy of Sciences, 72 Wenhua Road, Shenyang 110016, China; \\ xflei13b@imr.ac.cn (X.L.); zqzhang@imr.ac.cn (Z.Z.); ylhao@imr.ac.cn (Y.H.); ryang@imr.ac.cn (R.Y.) \\ 2 Institute of Metal Research, University of Chinese Academy of Sciences, Beijing 100049, China \\ 3 School of Engineering, Edith Cowan University, 270 Joondalup Drive, Joondalup, Perth, WA 6027, Australia; \\ liuyujing555@163.com \\ * Correspondence: lmdong@imr.ac.cn (L.D.); lczhangimr@gmail.com or 1.zhang@ecu.edu.au (L.-C.Z.); \\ Tel.: +86-242-397-1942 (L.D.); +61-863-042-322 (L.-C.Z.)
}

Academic Editor: Elena Pereloma

Received: 22 March 2017; Accepted: 3 April 2017; Published: 10 April 2017

\begin{abstract}
Microstructure, texture evolution, and mechanical properties of $\mathrm{Ti}-6 \mathrm{Al}-1.5 \mathrm{Cr}-2.5 \mathrm{Mo}-$ 0.5Fe-0.3Si (VT3-1) titanium alloy processed by multi-pass drawing and subsequent isothermal annealing were systematically investigated. A fiber-like microstructure is formed after warm drawing at $760{ }^{\circ} \mathrm{C}$ with $60 \%$ area reduction. After isothermal annealing, the samples deformed to different amounts of area reduction show a similar volume fraction $(80 \%)$ of $\alpha$ phase, while the sample deformed to $60 \%$ exhibits a homogeneous microstructure with a larger grain size $(5.8 \mu \mathrm{m})$. The major texture component of $\alpha$ phase developed during warm drawing is centered at a position of $\left\{\phi_{1}=10^{\circ}, \phi=65^{\circ}, \phi_{2}=0^{\circ}\right\}$. The textures for annealed samples are almost along the orientation of original deformation textures and show significant increases in orientation density and volume fraction compared with their deformed states. In addition, for the drawn samples, the ultimate tensile strength increases but the ductility decreases with increasing drawing deformation. A negative slope of yield strength of annealed samples versus grain size $\left(d^{-1 / 2}\right)$ is found due to the difference between texture softening for as-rolled + annealed state and texture hardening for drawn + annealed state. The mechanical properties of annealed samples are found to be strongly dependent on grain size and texture, resulting in the balance of the strength and ductility.
\end{abstract}

Keywords: titanium alloy; warm drawing; isothermal annealing; texture evolution; mechanical properties

\section{Introduction}

Titanium alloys have been used in the aircraft industry and marine engineering due to their high strength-to-weight ratio, good ductility, excellent fatigue properties, and corrosion resistance. In particular, two-phase titanium alloys are widely used as structural materials owing to their high strength and adequate ductility [1-4]. Among them, the Ti-6Al-1.5Cr-2.5Mo-0.5Fe-0.3Si alloy (known as VT3-1) is a typical two-phase titanium alloy, mainly used for gas turbine blades and fasteners owing to the balance of strength and ductility, toughness, and temperature capability up to $400-450^{\circ} \mathrm{C}[5,6]$.

In general, $\alpha$ and $\alpha+\beta$ titanium alloys, as well as other hexagonal close-packed (HCP) metals such as magnesium alloys [7], exhibit distinct textures and a pronounced anisotropy in 
mechanical properties as a result of the inherent deformation mechanism of the hexagonal crystal structure [8-14]. It was reported that there exists a cluster of $\alpha$ phases with sharp local texture called macrozones in semi-finished products such as billets [15,16]. It was also revealed that the evolution of microstructure and crystallographic texture are associated with primary recrystallization in titanium alloys $[1,17,18]$. So, in principle, thermo-mechanical processing routes determine the types of texture components together with the microstructures. Although a series of systematical studies have been performed on the texture of titanium alloys in the process of deformation and post-deformation heat treatment [19-25], limited literature is available on texture evolution of VT3-1 titanium alloys fabricated by multi-pass warm drawing and subsequent isothermal annealing.

To achieve the desired mechanical properties of bar materials, a comprehensive understanding of the relationship between microstructure, texture, and mechanical properties during drawing and subsequent heat treatment is needed. In particular, an extra opportunity of designing the properties of titanium alloys may be offered by understanding and manipulating various microstructures and crystallographic textures. In this work, the microstructure and texture evolution of VT3-1 titanium alloy during multi-pass warm drawing and subsequent isothermal annealing were systematically investigated. Furthermore, the influences of the microstructures and textures of deformation/recrystallization on its mechanical properties were also discussed.

\section{Materials and Methods}

The material used for the current study was a commercial Ti-6Al-1.5Cr-2.5Mo-0.5Fe-0.3Si (VT3-1) alloy with a chemical composition composed of $5.98 \% \mathrm{Al}, 1.48 \% \mathrm{Cr}, 2.57 \% \mathrm{Mo}, 0.52 \% \mathrm{Fe}, 0.30 \% \mathrm{Si}$, and Ti balance (wt \%). The $\beta$ transus temperature measured by the metallographic method was $\sim 965{ }^{\circ} \mathrm{C}$. When this alloy was heated at $960^{\circ} \mathrm{C}$ for $1 \mathrm{~h}$ followed by water quenching, its microstructure was composed of martensite and a small amount of primary $\alpha$ phase; yet when this alloy was treated at $970{ }^{\circ} \mathrm{C}$ for $1 \mathrm{~h}$ followed by water quenching, its microstructure was only composed of martensite. The received rolled bar of $25 \mathrm{~mm}$ diameter was drawn to $16 \mathrm{~mm}$ in diameter at $760{ }^{\circ} \mathrm{C}$ (in the $\alpha+\beta$ phase field) by 11 passes. The accumulated strain during warm drawing was calculated by:

$$
\varepsilon=\ln \left(D_{0} / D_{1}\right)^{2}
$$

where $D_{0}$ was the initial diameter of bar and $D_{1}$ was the diameter after drawing. Three groups of bars with different area reductions of $0 \%, \sim 30 \%$, and $\sim 60 \%$ were selected to examine the microstructure and texture. The details of the bars are listed in Table 1. Furthermore, all drawn samples were treated at $880^{\circ} \mathrm{C}$ for $2 \mathrm{~h}$ followed by furnace cooling to $650^{\circ} \mathrm{C}$, and then isothermally held for $2 \mathrm{~h}$ followed by air cooling to room temperature. Three isothermally annealed (IA) groups were selected and hereafter named as follows: as-received + IA bar, 30\% warm-drawn + IA bar and 60\% warm-drawn + IA bar.

Table 1. Experimental data of the Ti-6Al-1.5Cr-2.5Mo-0.5Fe-0.3Si (VT3-1) alloy bar samples.

\begin{tabular}{cccc}
\hline Sample State & Diameter, $\mathbf{m m}$ & Area Reduction, $\%$ & Accumulated Strain \\
\hline As received & 25.40 & 0 & 0 \\
30\% warm-drawn & 20.90 & 32.3 & 0.39 \\
$60 \%$ warm-drawn & 16.18 & 59.4 & 0.90 \\
\hline
\end{tabular}

In order to eliminate the effect of heterogeneity of the edge region caused by the drawing process [26,27], all the tested samples were obtained from the center of the bar, as schematically outlined in Figure 1. 


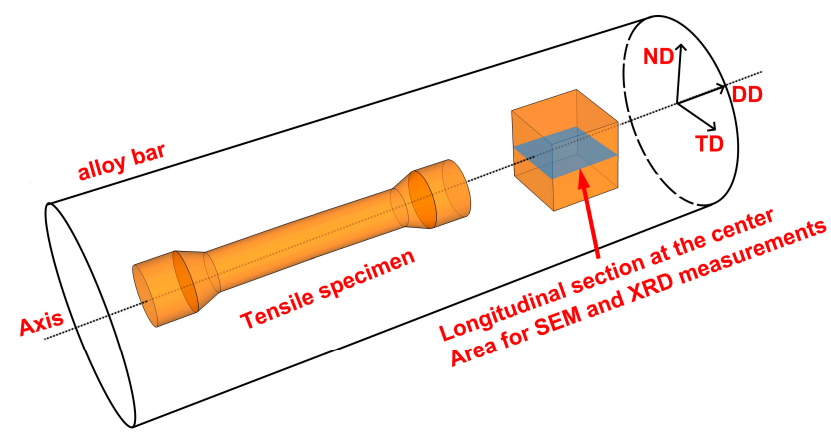

Figure 1. A schematic diagram of sampling location in VT3-1 alloy bars. The DD, ND and TD represent the drawing direction, normal direction and transverse direction, respectively. SEM: scanning electron microscopy; XRD: X-ray diffraction.

The microstructural characterizations were carried out using a Shimadzu SSX-550 scanning electron microscope (SEM) (Shimadzu Corporation, Tokyo, Japan). The specimens used for microstructure observation were grinded with $\mathrm{SiC}$ papers up to 2000 grits, polished with $\mathrm{SiO}_{2}$ emulsion and finally etched for $8 \mathrm{~s}$ in a solution of $5 \% \mathrm{HF}, 10 \% \mathrm{HNO}_{3}$, and $85 \%$ water. The mean grain size of the primary $\alpha$ phase was measured using the linear intercept method and the volume fraction of the $\alpha$ phase was estimated using image analysis from SEM images [28,29]. A D8 Discover X-ray diffractometer (XRD) with $\mathrm{Cu} \mathrm{K}-\alpha$ radiation (Bruker AXS GmbH, Karlsruhe, Germany) was used to examine the phase components and characterize the macrotexture. The specimens used for the XRD experiments were grinded with $\mathrm{SiC}$ papers up to 1500 grits and polished with $\mathrm{SiO}_{2}$ emulsion. The (1010), (0002), and (1011) incomplete pole figures of the $\alpha$ phase $(c / a=1.587)$ were measured first. The texture analysis was carried out with the TEXEval V2.0 software package (Bruker AXS $\mathrm{GmbH}$, Karlsruhe, Germany, 2000). Then, the inverse pole figures (IPFs) were calculated based on an assumption, namely, geometric symmetry was indexed in the orthorhombic $m m m$ system. The orientation distribution functions (ODFs) with the Bunge system $\left(\phi_{1}-\phi-\phi_{2}\right)$ were calculated by using the harmonic method [30]. The tensile specimens had a gauge diameter of $10 \mathrm{~mm}$ and a gauge length of $60 \mathrm{~mm}$ according to the standard of ISO 6892-1:2009. The tensile axis was parallel to the drawing direction. Room temperature tensile tests were performed at a constant cross-head speed of $1 \mathrm{~mm} / \mathrm{min}$ on a SANS-CMT 5205 testing machine (MTS Systems Corporation, Shenzhen, China). The strain rate of tensile specimens was $0.00028 \mathrm{~s}^{-1}$.

\section{Results and Discussion}

\subsection{Microstructure Characteristics}

Figure 2 compares the SEM micrographs of VT3-1 alloy after warm drawing and isothermal annealing. Figure $2 \mathrm{a}$,c,e show the microstructures of as-received, 30\%, and $60 \%$ warm-drawn samples, respectively, and their corresponding microstructures of IA states are shown in Figure $2 \mathrm{~b}, \mathrm{~d}, \mathrm{f}$, respectively. The as-received sample contains elongated primary $\alpha$, equiaxed primary $\alpha$, and $\beta$ transformed microstructures (Figure 2a). The $\alpha$ grains are gradually elongated with increasing drawing ratio (Figure 2c) and they are almost deformed into a fiber-like microstructure after $60 \%$ drawing deformation (Figure 2e). The mean primary $\alpha$ grain sizes (along the transverse direction (TD)) of as-received, 30\%, and $60 \%$ warm-drawn samples are 3.7, 2.9, and $1.9 \mu \mathrm{m}$, respectively, and their corresponding length/width ratios are 2.2, 5.8, and 15.2, respectively. Moreover, the morphology of secondary $\alpha$ phase in the $\beta$ transformed microstructure changes from acicular shape to platelet shape (Figure 2a,c,e). Simultaneously, the volume fraction of the total $\alpha$ phase is $\sim 55 \%$ for the as-received sample and increases up to $\sim 68 \%$ for the $30 \%$ warm-drawn sample, then grows slowly to $\sim 70 \%$ for the $60 \%$ warm-drawn sample. These microstructural changes can be attributed to the drawing deformation and the $\beta \rightarrow \alpha$ phase transformation. 


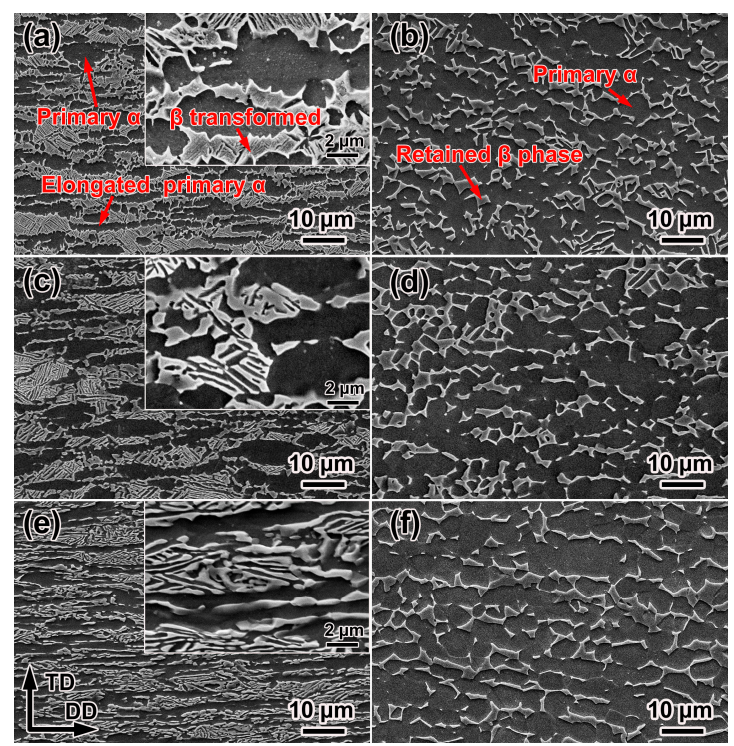

Figure 2. SEM micrographs of VT3-1 alloy after warm drawing and isothermal annealing: (a) as-received state; (b) as-received + isothermally annealed (IA) state; (c) 30\% warm-drawn state; (d) 30\% warm-drawn + IA state; (e) 60\% warm-drawn state; (f) 60\% warm-drawn + IA state.

After isothermal annealing, the mean primary $\alpha$ grain sizes (along TD) of $0 \%, 30 \%$, and $60 \%$ warm-drawn samples are 4.6, 5.1, and $5.8 \mu \mathrm{m}$, respectively, and the volume fraction of the primary $\alpha$ phase in all these samples is maintained as $\sim 80 \%$, as shown in Figure $2 b, d, f$. The retained $\beta$ phase is distributed mostly in the $\alpha$ grain boundaries and grain triple points, but the globularization process of the secondary $\alpha$ phase is not yet complete for the as-received + IA sample. Furthermore, the microstructure becomes more homogeneous with increasing drawing deformation. The differences in microstructure for IA samples drawn to different deformations are attributed to the changes in crystal defect and strain energy which can promote the recrystallization and growth of grains during subsequent heat treatment.

\subsection{X-ray Diffraction (XRD) and Texture Analysis}

Figure 3 depicts the XRD patterns of VT3-1 alloy under different processing conditions. It can be seen that all samples are composed of $\alpha$ and $\beta$ phases. Due to the low intensity of $\beta$ phase peaks and their positions being close to $\alpha$ phase peaks, it was difficult to record pole figures (PFs) of $\beta$ phase, and, thus, only the texture of $\alpha$ phase was studied in this work.

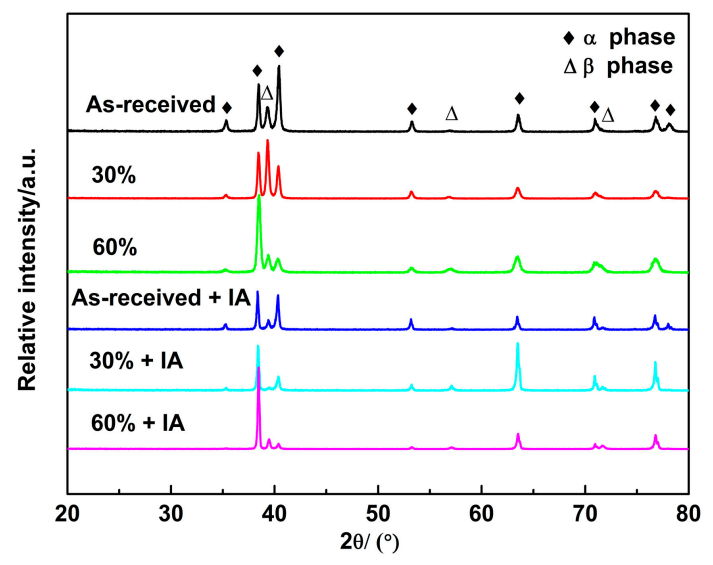

Figure 3. XRD patterns of VT3-1 alloy under different processing conditions. 
In order to examine the complete macrotexture features of the $\alpha$ phase (primary $\alpha$ phase and secondary $\alpha$ phase), IPFs and ODFs were obtained and presented. For a bar material, the fiber texture can be characterized by means of IPFs, namely the distributions of the crystal orientation relative to drawing direction (DD) and transverse direction (TD) [31]. The main textures usually can be seen in the first section $\left(\phi_{1}=0^{\circ}\right)$ of the ODF for titanium alloys [17], and, thus, the first section as well as relevant sections containing the maximum of the ODF are presented to describe the texture clearly.

Figure 4 presents the IPFs of the alloy after warm drawing and isothermal annealing. For the as-received state (Figure 4a), crystallographic directions of $\langle 10 \overline{1} 0>$ and $\langle 11 \overline{2} 0>$ are most likely parallel to the DD, and the $<10 \overline{1} 0>$ / / DD pair with an intensity of 2.85 is the main component. Meanwhile, the observed pair for the TD is <0001> / /TD (i.e., crystallographic c-axis//TD) with an intensity of 2.19. Similar orientations can be observed in 30\% (Figure 4c) and 60\% (Figure 4e) warm-drawn samples, but with the following differences. First, the intensity of the $<10 \overline{10}>/ /$ DD pair is increasing and crystals are tilted from the $\langle 11 \overline{2} 0>$ toward $<10 \overline{1} 0>$ with increasing drawing deformation. Second, the $c$-axis / /TD pair has been tilted approximately $10^{\circ}-15^{\circ}$ from the $<0001>$ towards $<10 \overline{1} 0>$. Such changes in orientation can be attributed to the increased number of grains and the grain rotations during drawing. After $60 \%$ warm drawing, the maximum intensity is obtained, i.e., $<10 \overline{1} 0>/ / D D$ pair with an intensity of 5.45 and $c$-axis/ /TD pair with an intensity of 2.84. The two basic texture types, i.e., the basal texture (B-texture) and the transversal texture (T-texture) [32] where the (0001) planes are parallel to the deformation plane and perpendicular to the deformation plane, respectively, are used to describe $\alpha$ deformation textures for rolled sheets. In this work, the T-texture for the drawn bar is referenced when the $c$-axis is perpendicular to the drawing direction (DD). There is a strong quasi T-fiber texture (i.e., the $c$-axis aligned with the TD) during warm drawing. After isothermal annealing, no significant change in orientation distribution is identified but the intensity of texture increases with increasing drawing deformation (Figure $4 \mathrm{~b}, \mathrm{~d}, \mathrm{f}$ ), which indicates that the crystal growth including initially deformed grains and newly recrystallized grains during isothermal annealing depends on the initial preferred orientations [17].
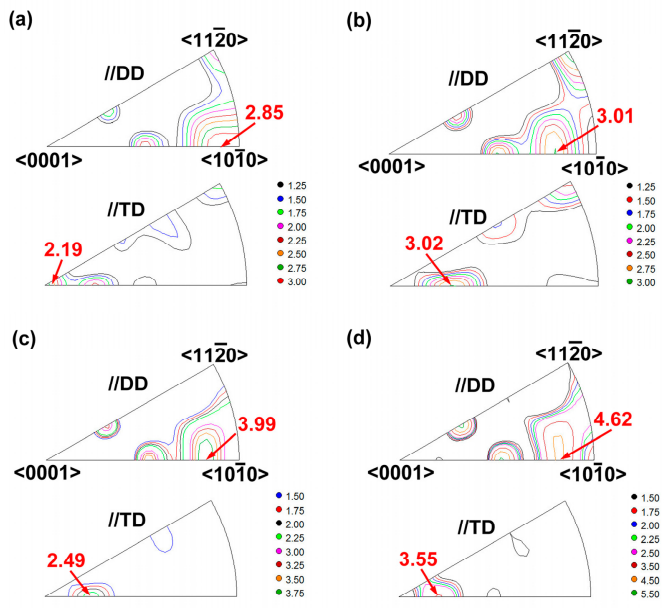

(d)
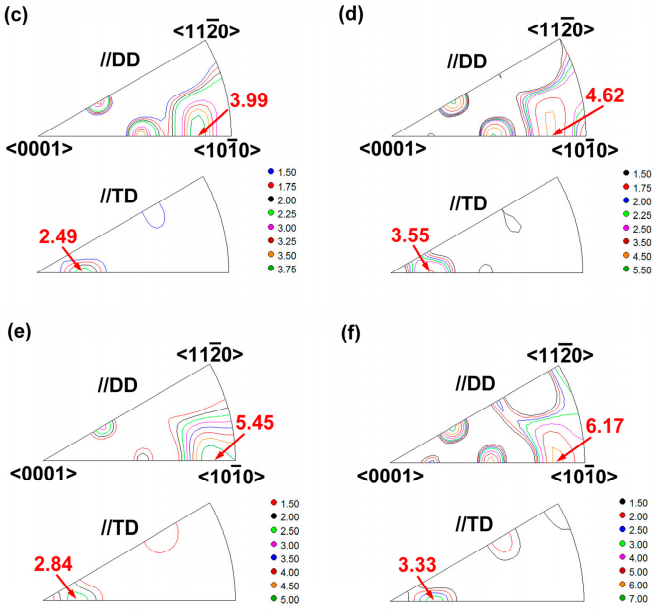

Figure 4. Representation of inverse pole figures (IPFs) corresponding to warm-drawn and IA states: (a) as-received state; (b) as-received + IA state; (c) 30\% warm-drawn state; (d) 30\% warm-drawn + IA state; (e) $60 \%$ warm-drawn state; (f) $60 \%$ warm-drawn + IA state. 
Figure 5 shows the ODF sections corresponding to warm-drawn states. For as-received state (Figure 5a), the high orientation densities are obtained at $\phi_{1}=0^{\circ}$ and $\phi_{1}=15^{\circ}$ sections. The maximum of the ODFs reaches 6.22 at the position of $\left\{\phi_{1}=0^{\circ}, \phi=70^{\circ}, \phi_{2}=30^{\circ}\right\}$, i.e., close to (0111) [2110], which belongs to quasi T-texture (with $c$-axis titled $\sim 30^{\circ}$ from TD to normal direction (ND)). Meanwhile, the second highest orientation density of 5.16 is observed around the position of $\left\{\phi_{1}=15^{\circ}, \phi=60^{\circ}\right.$, $\left.\phi_{2}=0^{\circ}\right\}$, i.e., close to $(\overline{1} 2 \overline{1} 2)[10 \overline{1} 0]$. Compared with $\left\{\phi_{1}=0^{\circ}, \phi=70^{\circ}, \phi_{2}=30^{\circ}\right\}, c$-axis of $\left\{\phi_{1}=15^{\circ}\right.$, $\phi=60^{\circ}, \varphi_{2}=0^{\circ}$ is titled $\sim 15^{\circ}$ and is rotated $30^{\circ}$. A comparison of the $30 \%$ warm-drawn state (Figure $5 b$ ) with as-received state shows that the center of the main peak changes into $\left\{\phi_{1}=15^{\circ}\right.$, $\left.\phi=65^{\circ}, \phi_{2}=0^{\circ}\right\}$ with the orientation density of 7.60. Similarly, there is a significant increase in orientation density near the position of $\left\{\phi_{1}=10^{\circ}, \phi=65^{\circ}, \phi_{2}=0^{\circ}\right\}$ (Figure $5 c$ ) for $60 \%$ warm-drawn state and this orientation density reaches 8.62. Therefore, the main texture component is near $\left\{\phi_{1}=10^{\circ}\right.$, $\left.\phi=65^{\circ}, \phi_{2}=0^{\circ}\right\}$ for warm-drawn state.

(a)
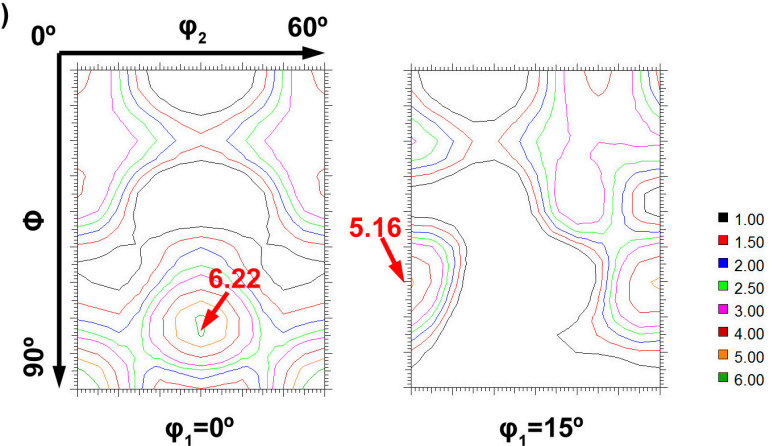

(b)
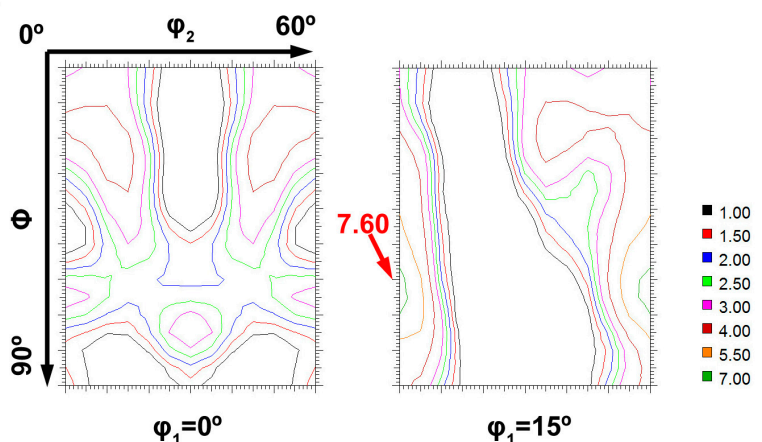

(c)
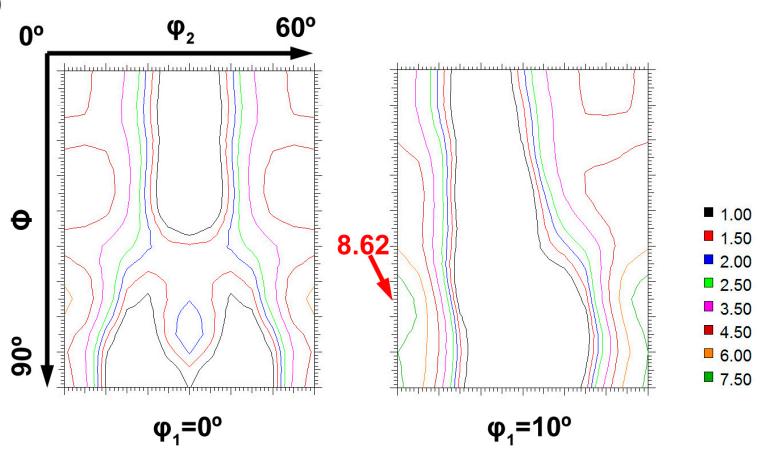

Figure 5. Representation of orientation distribution function (ODF) sections at constant $\phi_{1}$ corresponding to warm-drawn states: (a) as-received state: $\phi_{1}=0^{\circ}$ and $\phi_{1}=15^{\circ} ;(\mathbf{b}) 30 \%$ warm-drawn state: $\phi_{1}=0^{\circ}$ and $\phi_{1}=15^{\circ}$; (c) $60 \%$ warm-drawn state: $\phi_{1}=0^{\circ}$ and $\phi_{1}=10^{\circ}$.

Figure 6 shows the ODF sections corresponding to post-deformation IA states. For as-received + IA state (Figure 6a), the maximum value of ODFs reaches 7.23 at the position of $\left\{\phi_{1}=15^{\circ}, \phi=60^{\circ}\right.$, $\left.\phi_{2}=0^{\circ}\right\}$ with a large spread around it, and a secondary peak around the position of $\left\{\phi_{1}=0^{\circ}, \phi=65^{\circ}\right.$, 
$\phi_{2}=30^{\circ}$ \} reaches 6.58. A comparison of the as-received state with its subsequent IA state indicates that recrystallization strengthens the deformation textures in orientation density, but there is only fairly limited change in its main texture components (Figures 5a and 6a). It indicates that the textures during recrystallization are attributed to preferential grain growth which is influenced by the inheritance of deformation texture. A similar trend is observed in the 30\% warm-drawn + IA sample (Figure 6b). The maximum orientation density reaches 10.75 at the position of $\left\{\phi_{1}=10^{\circ}, \phi=65^{\circ}, \phi_{2}=0^{\circ}\right\}$. However, in the case of $60 \%$ warm-drawn + IA state, a large number of grains have slightly changed their orientations along $\phi$, and the main component is characterized by another high density (Figure $6 c$ ) around the position of $\left\{\phi_{1}=15^{\circ}, \phi=45^{\circ}, \phi_{2}=0^{\circ}\right\}$, i.e., close to (12) 13$)$ [10 10$]$. Meanwhile, other types of textures also occur and increase orientation density, such as $\left\{\phi_{1}=0^{\circ}, \phi=10^{\circ}, \phi_{2}=0^{\circ}\right\}$ and $\left\{\phi_{1}=0^{\circ}\right.$, $\phi=60^{\circ}, \phi_{2}=30^{\circ} \mathrm{\}}$. Thus, the texture evolution during recrystallization with increasing drawing deformation can be roughly depicted as the following two stages. In the first stage, the texture is strengthened and the main texture components undergo limited change within 30\% drawing deformation, since the oriented nucleation and growth of grains become dominant during subsequent isothermal annealing. It is worth noting that, even though an additional $\sim 15 \%$ of $\beta$ phase has transformed to $\alpha$ phase, new texture has not been formed in this stage. In the second stage, the main texture during recrystallization in this alloy, initially deformed by $60 \%$ warm drawing, has been shifted into a new component, i.e., $\left\{\phi_{1}=15^{\circ}, \phi=45^{\circ}, \phi_{2}=0^{\circ}\right\}$.

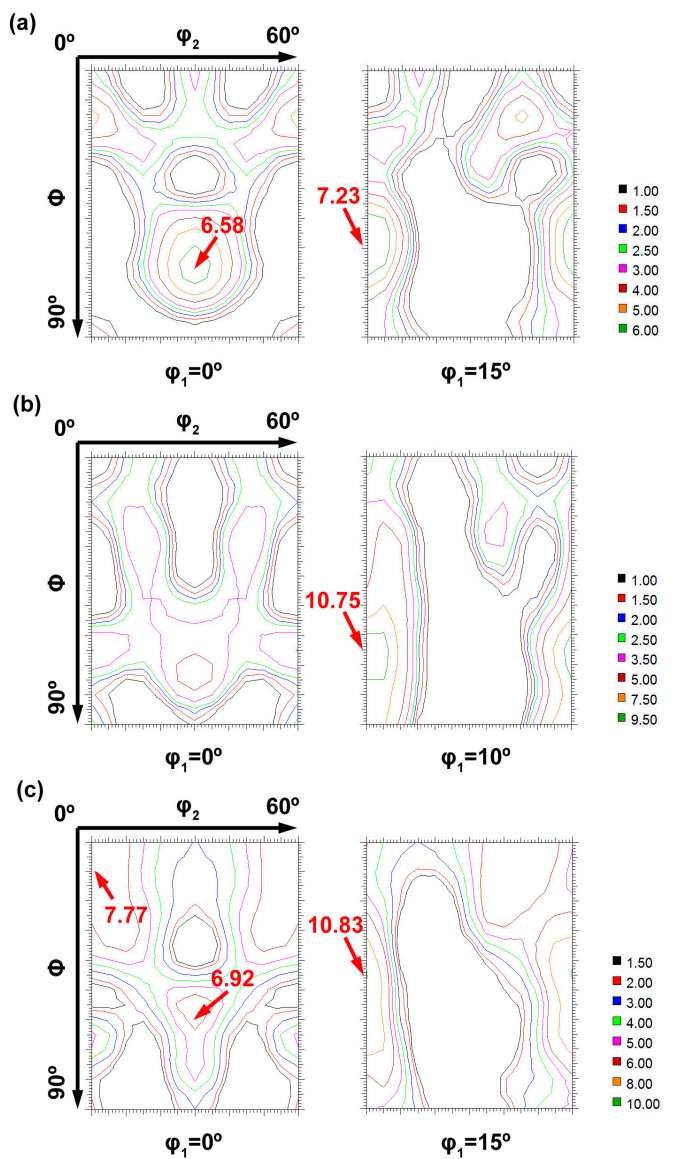

Figure 6. Representation of ODF sections at constant $\phi_{1}$ corresponding to IA states: (a) as-received + IA state: $\phi_{1}=0^{\circ}$ and $\phi_{1}=15^{\circ} ;$ (b) $30 \%$ warm-drawn + IA state: $\phi_{1}=0^{\circ}$ and $\phi_{1}=10^{\circ} ;(\mathbf{c}) 60 \%$ warm-drawn + IA state: $\phi_{1}=0^{\circ}$ and $\phi_{1}=15^{\circ}$.

Based on the ODFs data, the main observed texture components for the $\alpha$ phase with corresponding volume fraction (misorientation tolerance of $15^{\circ}$ ) and texture index are summarized in 
Table 2. Overall, the texture index is increasing with increasing drawing deformation but the texture increases nonlinearly. It can be seen that there is a sharp increase after 30\% drawing deformation (from 2.51 to 4.25 ), while a slight increase from 4.25 , corresponding to $30 \%$ drawing deformation, to 4.53 , corresponding to $60 \%$ drawing deformation. A similar trend on texture index is observed in post-deformation IA samples. It suggests that the texture index for deformed and annealed states is more sensitive to the drawing deformation in the first stage.

Table 2. Obtained texture characteristics in the alloy after warm drawing and isothermal annealing.

\begin{tabular}{|c|c|c|c|c|c|c|c|}
\hline \multirow{2}{*}{ Sample State } & \multicolumn{3}{|c|}{ Euler Angles, ${ }^{\circ}$} & \multirow{2}{*}{$\begin{array}{l}\text { Orientation } \\
\text { Density }\end{array}$} & \multirow{2}{*}{$\begin{array}{l}\text { Texture Component, } \\
\sim(\text { hkil)[uvtw] }\end{array}$} & \multirow{2}{*}{$\begin{array}{l}\text { Volume } \\
\text { Fraction, \% }\end{array}$} & \multirow{2}{*}{ Texture Index } \\
\hline & $\phi_{1}$ & $\phi$ & $\phi_{2}$ & & & & \\
\hline \multirow{3}{*}{ As-received } & 0 & 70 & 30 & 6.22 & $(01 \overline{1} 1)[2 \overline{11} 0]$ & 2.67 & \multirow{3}{*}{2.51} \\
\hline & 15 & 60 & 0 & 5.16 & $(\overline{1} 2 \overline{1} 2)[10 \overline{1} 0]$ & 2.87 & \\
\hline & 0 & 0 & 0 & 4.36 & 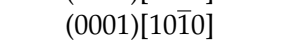 & 3.90 & \\
\hline \multirow{2}{*}{$30 \%$ warm-drawn } & 15 & 65 & 0 & 7.60 & $(\overline{1} 2 \overline{1} 2)[10 \overline{1} 0]$ & 4.46 & \multirow{2}{*}{4.25} \\
\hline & 0 & 25 & 10 & 4.69 & $(\overline{1} 3 \overline{2} 9)[10 \overline{1} 0]$ & 3.89 & \\
\hline \multirow{2}{*}{$60 \%$ warm-drawn } & 10 & 65 & 0 & 8.62 & $(\overline{1} 2 \overline{1} 2)[10 \overline{1} 0]$ & 5.29 & \multirow{2}{*}{4.53} \\
\hline & 0 & 35 & 0 & 5.53 & $(\overline{1} 2 \overline{1} 5)[10 \overline{1} 0]$ & 5.16 & \\
\hline \multirow{3}{*}{ As-received + IA } & 15 & 60 & 0 & 7.23 & $(\overline{1} 2 \overline{1} 2)[10 \overline{1} 0]$ & 2.94 & \multirow{3}{*}{3.77} \\
\hline & 0 & 65 & 30 & 6.58 & $(01 \overline{1} 1)[2 \overline{11} 0]$ & 3.17 & \\
\hline & 0 & 15 & 0 & 5.36 & $(0001)[10 \overline{1} 0]$ & 3.76 & \\
\hline \multirow{2}{*}{$30 \%+\mathrm{IA}$} & 10 & 65 & 0 & 10.75 & $(\overline{1} 2 \overline{1} 2)[10 \overline{1} 0]$ & 6.12 & \multirow{2}{*}{8.09} \\
\hline & 0 & 70 & 30 & 6.04 & $(01 \overline{1} 1)[2 \overline{11} 0]$ & 4.91 & \\
\hline \multirow{3}{*}{$60 \%+\mathrm{IA}$} & 15 & 45 & 0 & 10.83 & $(\overline{1} 2 \overline{1} 3)[10 \overline{1} 0]$ & 8.39 & \multirow{3}{*}{10.95} \\
\hline & 0 & 10 & 0 & 7.77 & $(0001)[10 \overline{1} 0]$ & 7.16 & \\
\hline & 0 & 60 & 30 & 6.92 & $(01 \overline{1} 1)[2 \overline{11} 0]$ & 4.64 & \\
\hline
\end{tabular}

\subsection{Mechanical Properties}

It is generally known that mechanical properties of titanium alloys are affected by grain size, degree of work hardening, texture, etc. $[4,14,33]$. In order to test these effects, tensile properties (i.e., UTS: ultimate tensile strength, YS: yield strength, RA: reduction in area, and EL: elongation) for VT3-1 alloy in various states were evaluated.

The variation of tensile properties of drawn states as a function of drawing deformation is shown in Figure 7. The YS and UTS increase from $1037 \mathrm{MPa}$ and $1096 \mathrm{MPa}$ for as-received state to $1277 \mathrm{MPa}$ and $1310 \mathrm{MPa}$ for the $60 \%$ warm-drawn state, respectively, which can directly result from grain refinement (Figure 2) and work hardening (dislocation density). However, the RA and EL drop from $61.9 \%$ and $18.2 \%$ for as-received state to $46.1 \%$ and $10.1 \%$ for $60 \%$ warm-drawn state, respectively.

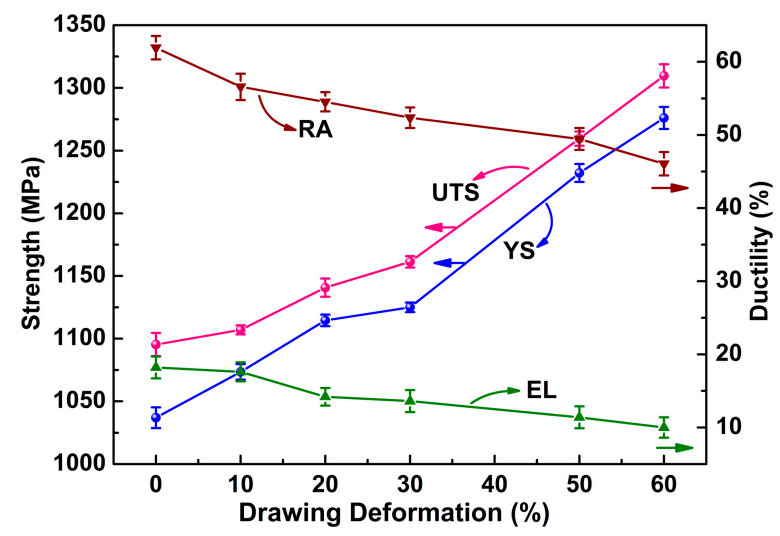

Figure 7. Variation of tensile properties of warm-drawn states as a function of drawing deformation. RA: reduction in area; UTS: ultimate tensile strength; YS: yield strength; EL: elongation. 
Figure 8 shows the variation of tensile properties of IA states as a function of drawing deformation. It can be observed that the IA samples show much higher and more stable ductility though the strength decreases compared with their deformed state, which results from recovery and recrystallization during isothermal annealing. Meanwhile, the strength of IA samples increases with increasing drawing deformation. Because the retained $\beta$ phase is dispersed at triple points of $\alpha$ phase and $\alpha$ phase bears a large fraction of total deformation [2,4], the similar volume fraction of equiaxed $\alpha$ grains $(\sim 80 \%)$ for IA samples is chosen to assess the mechanical properties. The Hall-Petch equation has been described for several classes of two-phase alloys [34,35]:

$$
\sigma=\sigma_{0}+K d^{-1 / 2}
$$

where $\sigma$ is the strength, $\sigma_{0}$ and $K$ are constants for the metal, and $d$ is the mean diameter of the grains. As shown in Figure 9, the values of YS and UTS for IA states are plotted against $d^{-1 / 2}$. The experimental values of strength are basically in line with fitted curve but show a different variation which disagrees with the standard Hall-Petch relationship (positive slope). For example, the YS of as-received + IA sample with mean grain size of $4.6 \mu \mathrm{m}$ is $950 \mathrm{MPa}$, while the YS of $60 \%$ + IA sample with $5.8 \mu \mathrm{m}$ is $991 \mathrm{MPa}$. It was mentioned previously that $\alpha$ phase develops sharp texture during drawing and annealing owing to a limited number of slip systems of HCP materials at room temperature, which may result in texture hardening or softening. So, texture modification during isothermal annealing is considered to be responsible for this trend (negative slope).

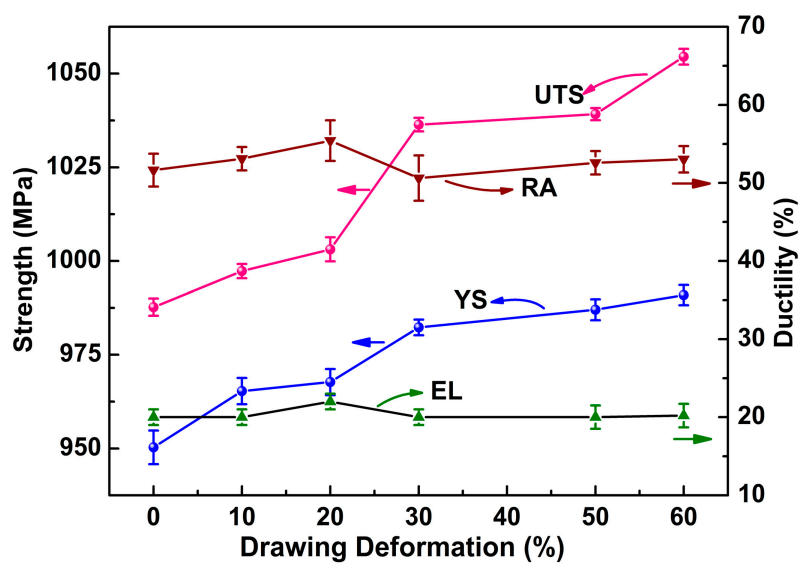

Figure 8. Variation of tensile properties of IA states as a function of drawing deformation.

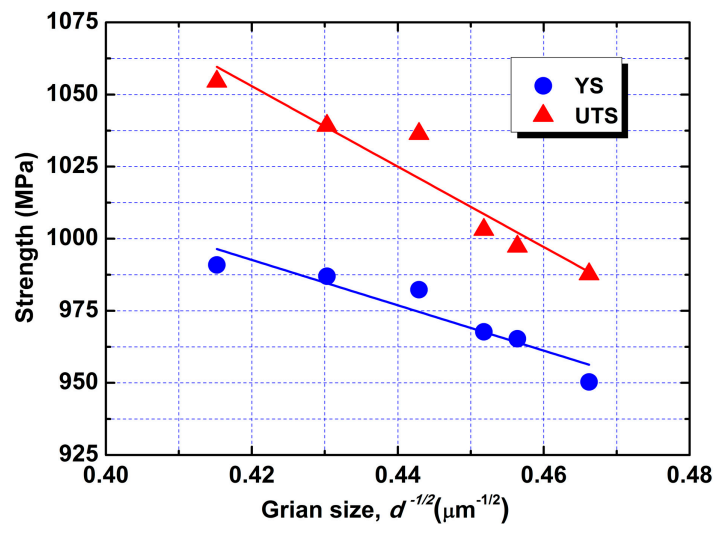

Figure 9. Yield strength (YS) and ultimate tensile strength (UTS) against grain size $\left(d^{-1 / 2}\right)$ for IA states. 
The Schmid factor ( $m$ value), as an important parameter of dislocation slip mechanism based on crystallographic model, can be applied to understand the effect of texture on yield-stress behavior:

$$
m=\cos \theta \cos \lambda
$$

where $\theta$ is the angle between the loading direction and the normal direction to slip plane, and $\lambda$ is the angle between the loading direction and slip direction. There are 24 possible activated slip systems (four types of slip systems), including 3 basal $<a>, 3$ prismatic $<a>, 6$ pyramidal $<a>$ and 12 pyramidal $<c+a>$ slip systems, which are the most important deformation systems in the hexagonal $\alpha$ phase for $\alpha / \beta$ titanium alloy $[25,36-39]$. The $m$ values for uniaxial tension are calculated based on the major texture components as shown in Table 3. Overall, basal $<$ a $>$ slip can hardly be activated because all the $m$ values for basal $<$ a $>$ slip are small, while prismatic $<a>$, pyramidal $<a>$ and pyramidal $<c+a>$ slips with higher $m$ values are activated preferentially.

Table 3. Schmid factor values based on obtained major texture components and main slip systems.

\begin{tabular}{|c|c|c|c|c|}
\hline \multirow{2}{*}{$\begin{array}{l}\text { Texture Component, } \\
\sim(\text { hkil)[uvtw] }\end{array}$} & \multicolumn{4}{|c|}{ Schmid Factor } \\
\hline & $\begin{array}{c}\text { Basal }<a>, \\
\{0001\}<11 \overline{2} 0>\end{array}$ & $\begin{array}{l}\text { Prismatic }<\mathrm{a}>\text {, } \\
\{10 \overline{1} 0\}<11 \overline{2} 0>\end{array}$ & Pyramidal $<a>,\{10 \overline{1} 1\}<11 \overline{2} 0>$ & $\begin{array}{c}\text { Pyramidal }<\mathrm{c}+\mathrm{a}> \\
\{10 \overline{1} 1\}<11 \overline{2} 3>\end{array}$ \\
\hline$(01 \overline{1} 1)[2 \overline{11} 0]$ & $0 ; 0 ; 0$ & $0.43 * ; 0.43 ; 0$ & $0 ; 0 ; 0.38 ; 0.38 ; 0.38 ; 0.38$ & $\begin{array}{c}0.2 ; 0.4 ; 0.2 ; 0.4 ; 0.4 ; 0.2 ; \\
0 ; 0 ; 0 ; 0 ; 0 ; 0\end{array}$ \\
\hline$(\overline{1} 2 \overline{1} 2)[10 \overline{1} 0]$ & $0.13 ; 0.12 ; 0.14$ & $0.45 ; 0.07 ; 0.38$ & $0.30 ; 0.37 ; 0.01 ; 0.14 ; 0.44 ; 0.36$ & $\begin{array}{c}0.05 ; 0.19 ; 0.07 ; 0.25 \\
0.32 ; 0.28 ; 0.48 * ; 0.45 \\
0.08 ; 0.14 ; 0.03 ; 0.17\end{array}$ \\
\hline$(0001)[10 \overline{1} 0]$ & $0 ; 0 ; 0$ & $0.43 ; 0 ; 0.43$ * & $0.38 ; 0.38 ; 0 ; 0 ; 0.38 ; 0.38$ & $\begin{array}{l}0 ; 0.2 ; 0 ; 0.2 ; 0.4 ; 0.4 ; \\
0.4 ; 0.4 ; 0 ; 0.2 ; 0 ; 0.2\end{array}$ \\
\hline$(\overline{1} 3 \overline{2} 9)[10 \overline{1} 0]$ & $0 ; 0 ; 0$ & $0.49^{*} ; 0.17 ; 0.32$ & $0.28 ; 0.28 ; 0.15 ; 0.15 ; 0.43 ; 0.43$ & $\begin{array}{l}0.05 ; 0.28 ; 0.05 ; 0.28 \\
0.43 ; 0.35 ; 0.43 ; 0.35 ; \\
0.03 ; 0.12 ; 0.03 ; 0.12\end{array}$ \\
\hline$(\overline{1} 2 \overline{1} 5)[10 \overline{1} 0]$ & $0 ; 0 ; 0$ & $0.43 * ; 0 ; 0.43$ & $0.38 ; 0.38 ; 0 ; 0 ; 0.38 ; 0.38$ & $\begin{array}{l}0 ; 0.2 ; 0 ; 0.2 ; 0.4 ; 0.4 ; \\
0.4 ; 0.4 ; 0 ; 0.2 ; 0 ; 0.2\end{array}$ \\
\hline$(\overline{1} 2 \overline{1} 3)[10 \overline{1} 0]$ & $0.14 ; 0.03 ; 0.17$ & $0.47 ; 0.18 ; 0.3$ & $0.24 ; 0.29 ; 0.07 ; 0.24 ; 0.47 ; 0.36$ & $\begin{array}{c}0.04 ; 0.22 ; 0.12 ; 0.31 ; \\
0.32 ; 0.22 ; 0.49 * ; 0.42 \\
0.09 ; 0.09 ; 0.01 ; 0.11\end{array}$ \\
\hline
\end{tabular}

Values with "** are the highest $m$ values.

The Sachs model [25] was used to analyze the effect of crystal orientation and deformation mode on mechanical properties. This model assumes that polycrystalline materials can be treated as an arrangement of isolated single crystals without the effects of boundaries and other neighboring grains; meanwhile, homogeneous deformation occurs throughout each grain which bears the same external stress. Under these ideal conditions, crystal orientation is the only factor for activating slip systems. In a single grain, the Schmid law is given as:

$$
\sigma_{\mathrm{y}}=\tau_{C R S S} \times\left(\frac{1}{M_{\mathcal{C}}}\right)
$$

where $\tau_{C R S S}$ is critical resolved shear stress, $M_{\mathcal{C}}$ is comprehensive Schmid factor, and $\sigma_{\mathrm{y}}$ is yield strength. The $M_{c}$ can be calculated from the following equation:

$$
M_{\mathcal{C}}=\sum_{i=1}^{k} m\left(g_{i}\right) \times f\left(g_{i}\right)
$$

where $m\left(g_{i}\right)$ is Schmid factor of the characteristic orientation $g_{i}$ and $f\left(g_{i}\right)$ is the volume fraction of $g_{i}$ for the whole orientation space $k$. In Equation (5), the $m\left(g_{i}\right)$ is determined by the highest value of 24 possible activated slip systems. For polycrystalline materials, assuming that the only slip system 
would be activated in a single grain and no texture area has equal contribution to stress, an estimation of the effect of orientation on yield stress can be made. Combining Equations (4) and (5), the calculated yield stress $\left(\sigma_{c}\right)$ is defined as follows:

$$
\sigma_{c}=\sum_{i}^{3}\left[\left(\tau_{i} / m_{i}\right) \times f(i)\right]+\left(1-\sum_{i}^{3} f(i)\right) \times \sigma^{*}
$$

where $\tau_{i}$ is the $\tau_{C R S S}$ for activated slip systems (two or three observed preferred orientations for one state in Table 2), $f(i)$ is the volume fraction of preferred orientations, and $\sigma^{*}$ is the normalized yield stress. However, there is the lack of consensus on $\tau_{C R S S}$ and their ratios for different deformation systems in polycrystalline metals. Based on some previous experimental and simulated estimations on $\tau_{C R S S}[10,25,37,40]$, the parameters including $\tau_{C R S S}$ of $270 \mathrm{MPa}, \sigma^{*}$ of $877.8 \mathrm{MPa}$, and the $\tau_{C R S S}$ ratios of 1:1:3 for prismatic $<$ a $>$ :pyramidal $<$ a $>$ :pyramidal $<c+a>$ are employed in this work. The calculated yield stresses under different processing conditions are listed in Table 4 . The change in $\sigma_{\mathrm{c}}$ is limited in drawn samples compared to other factors, while IA samples are more likely to be affected by texture due to the increase of texture index. Interestingly, the varying trend of the calculated yield stress is in agreement with the experimental values, and the negative slope of the Hall-Petch relationship is found as displayed in Figure 9. Therefore, the textures for IA samples play a critical role in determining the yield stress besides the grain size. For the as-received + IA sample, the slight texture softening occurs because the soft orientation (highest $m$ value for prismatic <a> with low $\tau_{C R S S}$ ) has a larger volume fraction than some hard orientations. However, the $30 \%+$ IA and $60 \%+$ IA samples exhibit texture hardening owing to $\left\{\phi_{1}=10^{\circ}, \phi=65^{\circ}, \phi_{2}=0^{\circ}\right\}$ and $\left\{\phi_{1}=15^{\circ}, \phi=45^{\circ}, \phi_{2}=0^{\circ}\right\}$, respectively, which are the hard orientations with the highest $m$ values for pyramidal $<c+$ a $>$ with high $\tau_{C R S S}$.

Table 4. Calculated yield stresses under different processing conditions.

\begin{tabular}{cc}
\hline Sample State & Calculated Yield Stress, $\mathbf{M P a}$ \\
\hline As-received & 884.6 \\
30\% warm-drawn & 901.2 \\
$60 \%$ warm-drawn & 907.7 \\
As-received + IA & 875.5 \\
$30 \%+$ IA & 910.6 \\
$60 \%$ + IA & 913.4 \\
\hline
\end{tabular}

In summary, grain size and texture synergistically govern the strength level of drawn and annealed Ti-6Al-1.5Cr-2.5Mo-0.5Fe-0.3Si alloy. In order to obtain the balance of strength and ductility for $\alpha+\beta$ titanium alloys, the warm-drawing process is worth exploring not only for the grain refinement but also for texture hardening.

\section{Conclusions}

Microstructure and texture evolution of Ti-6Al-1.5Cr-2.5Mo-0.5Fe-0.3Si (VT3-1) alloy during multi-pass warm drawing and subsequent isothermal annealing have been systematically investigated and correlated with the mechanical properties. The main conclusions can be summarized as follows.

(1) For drawn samples, $\alpha$ grains are gradually elongated along the drawing direction with increasing deformation, and a fiber-like microstructure is formed after $60 \%$ warm-drawing deformation. After isothermal annealing, the microstructure is more homogeneous with increasing deformation, although the volume fraction of the $\alpha$ phase is similar.

(2) The fiber texture with orientations around the position of $\left\{\phi_{1}=10^{\circ}, \phi=65^{\circ}, \phi_{2}=0^{\circ}\right\}$, i.e., close to $(\overline{1} 2 \overline{1} 2)[10 \overline{1} 0]$, gradually becomes the major and stable type of texture during warm drawing. For IA samples, the textures during recrystallization show significant increases in texture intensity and in volume fraction compared to their deformed states due to a preferential grain growth 
along the orientation of original deformation textures. However, for the $60 \%+$ IA samples, the major orientation has been shifted into a new one with $c$-axis titled $\sim 20^{\circ}$ compared with $\left\{\phi_{1}=10^{\circ}\right.$, $\left.\phi=65^{\circ}, \phi_{2}=0^{\circ}\right\}$. The texture indices for deformed and annealed states are sensitive within the $30 \%$ drawing deformation.

(3) The samples processed by multi-pass warm drawing exhibit high strength and low ductility owing to significant grain refinement and work hardening. For IA samples, a high and stable ductility is obtained. Moreover, a negative slope of yield strength versus $d^{-1 / 2}$ is observed as a result of texture softening in as-received + IA samples but texture hardening in drawn + IA samples. The relationship between texture and yield strength indicates that texture developed during drawing is beneficial to improving strength of IA states.

Author Contributions: Xiaofei Lei and Limin Dong conceived and designed the experiments; Zhiqiang Zhang and Xiaofei Lei performed the experiments; Yujing Liu, Lai-Chang Zhang, and Yulin Hao analyzed and discussed the data; Xiaofei Lei wrote the paper; Rui Yang did the revision and direction of the work.

Conflicts of Interest: The authors declare no conflict of interest.

\section{References}

1. Lütjering, G.; Williams, J.C. Titanium, 2nd ed.; Springer: Berlin/Heidelberg, Germany, 2007; pp. $203-250$.

2. Liu, Y.J.; Li, X.P.; Zhang, L.C.; Sercombe, T.B. Processing and properties of topologically optimised biomedical Ti-24Nb-4Zr-8Sn scaffolds manufactured by selective laser melting. Mater. Sci. Eng. A 2015, 642, 268-278. [CrossRef]

3. Cui, C.; Hu, B.M.; Zhao, L.; Liu, S. Titanium alloy production technology, market prospects and industry development. Mater. Des. 2011, 32, 1684-1691. [CrossRef]

4. Ehtemam-Haghighi, S.; Liu, Y.J.; Cao, G.; Zhang, L.C. Influence of $\mathrm{Nb}$ on the $\beta \rightarrow \alpha$ martensitic phase transformation and properties of the newly designed Ti-Fe-Nb alloys. Mater. Sci. Eng. C 2015, 60, 503-510. [CrossRef] [PubMed]

5. Li, M.; Xiong, A.; Huang, W.; Wang, H.; Su, S.; Shen, L. Microstructural evolution and modelling of the hot compression of a TC6 titanium alloy. Mater. Charact. 2002, 49, 203-209. [CrossRef]

6. Ghasemi, E.; Zarei-Hanzaki, A.; Moemeni, S.; Ghambari, M.; Rezaee, M. An investigation into the warm deformation behavior of Ti-6Al-1.5Cr-2.5Mo-0.5Fe-0.3Si alloy. Mater. Sci. Eng. A 2016, 654, 264-270. [CrossRef]

7. Kim, W.J.; Hong, S.I.; Kim, Y.S.; Min, S.H.; Jeong, H.T.; Lee, J.D. Texture development and its effect on mechanical properties of an AZ61 Mg alloy fabricated by equal channel angular pressing. Acta Mater. 2003, 51, 3293-3307. [CrossRef]

8. Zhang, L.C.; Attar, H. Selective Laser Melting of Titanium Alloys and Titanium Matrix Composites for Biomedical Applications: A Review. Adv. Eng. Mater. 2016, 18, 463-475. [CrossRef]

9. Zhao, A.M.; Yang, H.; Fan, X.G.; Gao, P.F.; Zuo, R.; Meng, M. The flow behavior and microstructure evolution during $(\alpha+\beta)$ deformation of $\beta$ wrought TA15 titanium alloy. Mater. Des. 2016, 109, 112-122. [CrossRef]

10. Bieler, T.R.; Semiatin, S.L. The origins of heterogeneous deformation during primary hot working of Ti-6Al-4V. Int. J. Plast. 2002, 18, 1165-1189. [CrossRef]

11. Bridier, F.; Villechaise, P.; Mendez, J. Analysis of the different slip systems activated by tension in a $\alpha / \beta$ titanium alloy in relation with local crystallographic orientation. Acta Mater. 2005, 53, 555-567. [CrossRef]

12. Ehtemam-Haghighi, S.; Liu, Y.J.; Cao, G.; Zhang, L.C. Phase transition, microstructural evolution and mechanical properties of Ti-Nb-Fe alloys induced by Fe addition. Mater. Des. 2016, 97, 279-286. [CrossRef]

13. Fizanne-Michel, C.; Cornen, M.; Castany, P.; Péron, I.; Gloriant, T. Determination of hardness and elastic modulus inverse pole figures of a polycrystalline commercially pure titanium by coupling nanoindentation and EBSD techniques. Mater. Sci. Eng. A 2014, 613, 159-162. [CrossRef]

14. Wang, Y.N.; Huang, J.C. Texture analysis in hexagonal materials. Mater. Chem. Phys. 2003, 81, 11-26. [CrossRef]

15. Germain, L.; Gey, N.; Humbert, M.; Bocher, P.; Jahazi, M. Analysis of sharp microtexture heterogeneities in a bimodal IMI 834 billet. Acta Mater. 2005, 53, 3535-3543. [CrossRef]

16. Gey, N.; Bocher, P.; Uta, E.; Germain, L.; Humbert, M. Texture and microtexture variations in a near- $\alpha$ titanium forged disk of bimodal microstructure. Acta Mater. 2012, 60, 2647-2655. [CrossRef] 
17. Wagner, F.; Bozzolo, N.; Landuyt, O.V.; Grosdidier, T. Evolution of recrystallisation texture and microstructure in low alloyed titanium sheets. Acta Mater. 2002, 50, 1245-1259. [CrossRef]

18. Bozzolo, N.; Dewobroto, N.; Grosdidier, T.; Wagner, F. Texture evolution during grain growth in recrystallized commercially pure titanium. Mater. Sci. Eng. A 2005, 397, 346-355. [CrossRef]

19. Warwick, J.L.W.; Jones, N.G.; Bantounas, I.; Preuss, M.; Dye, D. In situ observation of texture and microstructure evolution during rolling and globularization of Ti-6Al-4V. Acta Mater. 2013, 61, 1603-1615. [CrossRef]

20. Hayama, A.O.F.; Lopes, J.F.S.C.; Silva, M.J.G.D.; Abreu, H.F.G.; Caram, R. Crystallographic texture evolution in Ti-35Nb alloy deformed by cold rolling. Mater. Des. 2014, 60, 653-660. [CrossRef]

21. Cojocaru, V.D.; Raducanu, D.; Gloriant, T.; Gordin, D.M.; Cinca, I. Effects of cold-rolling deformation on texture evolution and mechanical properties of Ti-29Nb-9Ta-10Zr alloy. Mater. Sci. Eng. A 2013, 586, 1-10. [CrossRef]

22. Prakash, D.G.L.; Honniball, P.; Rugg, D.; Withers, P.J.; Fonseca, J.Q.D.; Preuss, M. The effect of $\beta$ phase on microstructure and texture evolution during thermomechanical processing of $\alpha+\beta$ Ti alloy. Acta Mater. 2013, 61, 3200-3213. [CrossRef]

23. Du, Z.; Xiao, S.; Liu, J.; Lv, S.; Xu, L.; Kong, F.; Chen, Y. Hot deformation behavior of Ti-3.5Al-5Mo6V-3Cr-2Sn-0.5Fe alloy in $\alpha+\beta$ field. Metals 2015, 5, 216-227. [CrossRef]

24. Lium, Y.J.; Lim, S.J.; Wangm, H.L.; Houm, W.T.; Haom, Y.L.; Yangm, R.; Sercombem, T.B.; Zhang, L.C. Microstructure, defects and mechanical behavior of beta-type titanium porous structures manufactured by electron beam melting and selective laser melting. Acta Mater. 2016, 113, 56-67.

25. Zaefferer, S. A study of active deformation systems in titanium alloys: Dependence on alloy composition and correlation with deformation texture. Mater. Sci. Eng. A 2003, 344, 20-30. [CrossRef]

26. Zhao, T.Z.; Zhang, G.L.; Song, H.W.; Cheng, M.; Zhang, S.H. Crystallographic texture difference between center and sub-surface of thin cold-drawn pearlitic steel wires. J. Mater. Eng. Perform. 2014, 23, 3279-3284. [CrossRef]

27. Lee, J.W.; Baek, H.M.; Sun, K.H.; Son, I.H.; Bae, C.M.; Im, Y.T. The effect of the multi-pass non-circular drawing sequence on mechanical properties and microstructure evolution of low-carbon steel. Mater. Des. 2014, 55, 898-904. [CrossRef]

28. Dai, N.; Zhang, L.C.; Zhang, J.; Chen, Q.; Wu, M. Corrosion behaviour of selective laser melted Ti-6Al-4V alloy in $\mathrm{NaCl}$ solution. Corros. Sci. 2016, 102, 484-489. [CrossRef]

29. Zhang, L.C.; Das, J.; Lu, H.B.; Duhamel, C.; Calin, M.; Eckert, J. High strength Ti-Fe-Sn ultrafine composites with large plasticity. Scr. Mater. 2007, 57, 101-104. [CrossRef]

30. Dahms, M.; Bunge, H.J. The iterative series-expansion method for quantitative texture analysis. I. General outline. J. Appl. Crystallogr. 1989, 22, 439-447. [CrossRef]

31. Robertson, S.W.; Gong, X.Y.; Ritchie, R.O. Effect of product form and heat treatment on the crystallographic texture of austenitic Nitinol. J. Mater. Sci. 2006, 41, 621-630. [CrossRef]

32. Schillinger, W.; Bartels, A.; Gerling, R.; Schimansky, F.P.; Clemens, H. Texture evolution of the $\gamma$ - and the $\alpha / \alpha_{2}$-phase during hot rolling of $\gamma$-TiAl based alloys. Intermetallics 2006, 14, 336-347. [CrossRef]

33. Ghamarian, I.; Hayes, B.; Samimi, P.; Welk, B.A.; Fraser, H.L.; Collins, P.C. Developing a phenomenological equation to predict yield strength from composition and microstructure in $\beta$ processed Ti-6Al-4V. Mater. Sci. Eng. A 2016, 660, 172-180. [CrossRef]

34. Leyens, C.; Peters, M. Titanium and Titanium Alloys: Fundamentals and Applications, 1st ed.; Wiley-VCH Verlag GmbH: Weinheim, Germany, 2003; pp. 112-114.

35. Kumar, S.S.S.; Priyasudha, K.; Rao, M.S.; Raghu, T. Deformation homogeneity, mechanical behaviour and strain hardening characteristics of titanium severe plastically deformed by cyclic channel die compression method. Mater. Des. 2016, 101, 117-129. [CrossRef]

36. Nan, X.L.; Wang, H.Y.; Zhang, L.; Li, J.B.; Jiang, Q.C. Calculation of Schmid factors in magnesium: Analysis of deformation behaviors. Scr. Mater. 2012, 67, 443-446. [CrossRef]

37. Li, H.; Mason, D.E.; Bieler, T.R.; Boehlert, C.J.; Crimp, M.A. Methodology for estimating the critical resolved shear stress ratios of $\alpha$-phase Ti using EBSD-based trace analysis. Acta Mater. 2013, 61, 7555-7567. [CrossRef]

38. Liu, Y.J.; Wang, H.L.; Li, S.J.; Wang, S.G.; Wang, W.J.; Hou, W.T.; Hao, Y.L.; Yang, R.; Zhang, L.C. Compressive and fatigue behavior of beta-type titanium porous structures fabricated by electron beam melting. Acta Mater. 2017, 126, 58-66. [CrossRef] 
39. Liu, Y.J.; Li, S.J.; Hou, W.T.; Wang, S.G.; Hao, Y.L.; Yang, R.; Sercombe, T.B.; Zhang, L.C. Electron beam melted beta-type $\mathrm{Ti}-24 \mathrm{Nb}-4 \mathrm{Zr}-8 \mathrm{Sn}$ porous structures with high strength-to-modulus ratio. J. Mater. Sci. Technol. 2016, 32, 505-508. [CrossRef]

40. Fundenberger, J.J.; Philippe, M.J.; Wagner, F.; Esling, C. Modelling and prediction of mechanical properties for materials with hexagonal symmetry (zinc, titanium and zirconium alloys). Acta Mater. 1997, 45, 4041-4055. [CrossRef]

(c)

(C) 2017 by the authors. Licensee MDPI, Basel, Switzerland. This article is an open access article distributed under the terms and conditions of the Creative Commons Attribution (CC BY) license (http:/ / creativecommons.org/licenses/by/4.0/). 